\title{
Assessment of the parasitism potential of three parasitoids of fruit fly, Bactrocera spp. (Diptera: Tephritidae) under laboratory conditions
}

\author{
Muhammad Hamayoon Khan*, Niaz Hussain Khuhro, Muhammad
} Awais, Raza Muhammad Memon and Waseem Akbar

Plant Protection Division, Nuclear Institute of Agriculture (NIA), Tandojam-70060-Pakistan

*Corresponding author's email: mhkhan170@gmail.com

\section{Citation}

Muhammad Hamayoon Khan, Niaz Hussain Khuhro, Muhammad Awais, Raza Muhammad Memon and Waseem Akbar. Assessment of the parasitism potential of three parasitoids of fruit fly, Bactrocera spp. (Diptera: Tephritidae) under laboratory conditions. Pure and Applied Biology. Vol. 8, Issue 2, pp1579-1587. http://dx.doi.org/10.19045/bspab.2019.80099

\begin{tabular}{llll}
\hline \hline Received: 27/01/2019 & Revised: 29/04/2019 & Accepted: 23/05/2019 & Online First: 27/05/2019 \\
\hline \hline
\end{tabular}

\section{Abstract}

The parasitism potential of a pupal parasitoid, Dirhinus giffardii Silvestri and two larval-pupal parasitoids, Diachasmimorpha longicaudata (Ashmead) and Aganapis daci (Weld) was assessed against Bactrocera spp. under laboratory conditions. Three different types of hosts, viz. Bactrocera zonata (Saunders), Bactrocera dorsalis (Hendel) and Bactrocera cucurbitae (Coquillett) were reared on artificial larval diet and known number of pupae and larvae of each fruit fly species were offered to the respective parasitoids in glass cages in a no choice test. Results on the parasitism potential of $D$. giffardii towards pupae of different fruit fly species revealed that the highest per female parasitism was recorded on $B$. zonata $(16.72 \pm 1.67)$. Adult emergence percentage of $D$. giffardii did not differ significantly among all the three Bactrocera spp. Sex ratio of the emerged parasitoids revealed maximum percent females $(61.64 \pm 2.67)$ from pupae of B. cucurbitae. Similarly per female parasitism by $D$. longicaudata was also significantly the highest on larvae of $B$. zonata $(26.40 \pm 1.79)$ with maximum adult emergence percentage of $93.41 \pm 2.54$. Sex ratio of the emerged $D$. longicaudata did not differ significantly. Parasitism rate of $A$. daci was significantly the highest on larvae of $B$. zonata $(24.88 \pm 2.01)$ with insignificant differences in the adult emergence percentage. Sex ratio of $A$. daci showed that percent females from the emerged parasitoids were the highest $(54.2 \pm 3.44)$ on $B$. dorsalis. Relative collective parasitism per female by all the three fruit fly parasitoids revealed that highest parasitism rate $(23.7 \pm 2.26)$ was exhibited by $D$. longicaudata followed by $A$. daci $(22.72 \pm 2.14)$. The study manifested that $B$. zonata could be the ideal host for laboratory rearing of these parasitoids.

Keywords: Bactrocera; Emergence; Fruit fly; Host; Parasitoids; Parasitism; Sex ratio

Introduction

Fruit flies, Bactrocera spp. (Diptera: Tephritidae) are pests of great economic importance in the tropical and subtropical regions of the world [1]. This cosmopolitan distribution of fruit flies highlights their 
international importance in sustainable fruit and vegetable production as well as trade issues [2, 3]. High value exports of fruit (citrus, guava, mango etc.) and vegetables (especially cucurbits) significantly contribute in the economy of Pakistan [4]. However, being major quarantine pests of fruits and vegetables, fruit flies not only create hindrances in fruit and vegetable exports but also reduce their average $\mathrm{ha}^{-1}$ yield. In favorable conditions, production from the entire crop can be wiped out by these pests and the whole agricultural economy of the infested area could be ruined [5]. The genus Bactrocera, with about 651 described species, have been reported the most economically significant fruit fly genus. About 50 species in this genus are considered to be highly destructive and major polyphagous pests of horticultural and vegetable crops [6-8]. Among these the Bactocera cucurbitae (Coquillett), Bactocera dorsalis (Hendel) and Bactrocera zonata (Saunders) (Diptera: Tephritidae) inflict heavy losses to a wide range of fruits and vegetables in Pakistan.

Injudicious and frequent use of pesticides each year for the control of these pests are continuously affecting the biotic and abiotic factors of the environment [9]. Biological control is a fundamental component of Integrated Pest Management system [10]. Unlike chemical control method, it has no ill effects on the environment. In certain cases, biological control alone produced magnificent results in suppressing pest population eliminating the need for other control methods [11]. It has been demonstrated in previous studies that Aganapis daci (Weld) (Hymenoptera: Eucoilida), Dirhinus giffardii Silvestri (Hymenoptera: Chalcididae) and Diachasmimorpha longicaudata (Ashmead) (Hymenoptera: Braconidae) are important natural enemies of Bactrocera spp. Of these biological control agents, A. daci (originally described as Trybliographa daci Weld), was first collected in Malaysia and Borneo, and introduced into Hawaii as a potential biocontrol agent for $B$. dorsalis [12]. It has also been successfully reared on and released against Medfly in many European countries including Greece and France [13, 14]. D. giffardii is also an efficient pupal parasitoid of many fruit fly species. It is primitive of West Africa and has been effectively used in the biological control program in many countries for reducing Dipteran pest population [15-17]. D. longicaudata is a larval-pupal parasitoid of several fruit fly species and is native to Southeast Asia [17, 18]. It has been used in augmentative biological control programs against $B$. dorsalis [19]. Similarly, it is also widely spread in Pakistan with parasitism rate exceeding $36 \%$ on $B$. dorsalis in the foot hills. In Pakistan, A. daci together with $D$. longicaudata resulted in more than $44 \%$ parasitism of $B$. zonata in unsprayed orchards in the plains [20].

Production of natural enemies in an efficient and economical way is a prerequisite for biological control program. Considerable technological advances have been made in mass rearing of parasitoids and predators for augmentative biological management of the pests [21-23]. Similarly production of laboratory reared natural enemies may be enhanced by the provision of suitable host. From the last several years $D$. giffardii; $D$. longicaudata and $A$. daci have been documented from the mango and guava orchards of Sindh. Keeping this in view, the present study was designed to find out the parasitism potential of these parasitoids and hence, a suitable host for their proficient rearing.

\section{Materials and methods}

The experiment on parasitism potential of three parasitoids, viz. $D$. giffardii, $D$. longicaudata, and A. daci was conducted in the fruit fly rearing laboratory of Nuclear 
Institute of Agriculture (NIA) Tandojam under controlled conditions (26 \pm 1 and $65 \pm$ 5\% RH and $16 \mathrm{~h} \mathrm{L:} 8 \mathrm{~h}$ D photoperiod). Three different kinds of hosts, $B$. zonata, B. dorsalis and $B$. cucurbitae were reared on artificial larval diet containing wheat bran (26\%), sugar (12\%), dried torula yeast (3.6\%), Sodium benzoate $(0.1 \%)$, Methyl-phydroxybenzoate $(0.1 \%)$ and water $(58 \%)$. The adult fruit flies were provided with sugar and protein hydrolysate. For oviposition, plastic glasses having $0.5 \mathrm{~mm}$ holes around them were smeared internally with guava juice and placed in the adult cages. Eggs laid by females in these jars were collected and removed by fine hair brush. These eggs were further used for maintaining the culture by directly seeding (about $2.5 \mathrm{~g}$ ) on artificial diet $(2.5 \mathrm{~kg})$ in metallic trays. The trays were kept above the pupation substrate (saw dust) under laboratory conditions. The larval pop out for pupation started on 8-10 days after the eggs being seeded. The pupae were collected by sieving the saw dust regularly on daily basis till complete pupation of all the larvae. The strains of pupal parasite, D. giffardii, $D$. longicaudata and A. daci were maintained at the fruit fly rearing laboratory. $D$. giffardii were reared in glass cages $(30 \times 30 \times 30 \mathrm{~cm})$ on pupae of $B$. zonata whereas culture of $D$. longicaudata and $A$. daci were maintained on larvae of $B$. zonata in glass cages $(30 \times 30 \times 30$ $\mathrm{cm})$. For adult parasitoids artificial diet containing fresh solution $30 \%$ honey and $70 \%$ water) were provided through soaked cotton wigs impregnated with honey and water.

To find out the parasitism potential of $D$. giffardii five pairs of the parasitoid (5-6 days old) were released separately in glass jars $(18 \times 18 \times 18 \mathrm{~cm})$ containing 3 days old pupae (200) of one of the three fruit fly species, viz. B. zonata, B. dorsalis and B. cucurbitae. After $24 \mathrm{~h}$ the pupae were removed and placed in another jar for parasitoid emergence. The experiment was replicated 5 times. The data were regularly recorded on parasitism rate and emergence of wasps. The sex ratio of the emerged parasitoids was also accomplished carefully. Similarly for other two parasitoids, D. longicaudata and A. daci, 3-4 days old 300 larvae of each of the above mentioned fruit fly species were provided separately in Petri dishes on artificial diet placed in glass jars containing 5 pairs of one of the two species of parasitoids for $24 \mathrm{~h}$ period . After $24 \mathrm{~h}$, the larvae were removed in petri dishes and placed in another glass jar having saw dust for pupation. The pupae were collected after pupation and placed back in the glass jar for emergence. Data were regularly recorded on parasitism rate, emergence and sex ratios of the parasitoids.

\section{Statistical analysis}

Data recorded on parasitism rate, emergence and sex ratio of different parasitoids were subjected to analysis of variance (one-way ANOVA) using Statistical Software program IBM SPSS Statistics 20. Multiple comparisons among the means were made using Tukey's HSD test $(P<0.05)$.

\section{Results}

Results on the parasitism potential of $D$. giffardii on pupae of different Bactrocera species revealed that he highest per female parasitism was recorded on B. zonata $(16.72$ \pm 1.67 ) followed by parasitism of $15.04 \pm 0.87$ on B. zonata (Table 1). Significantly the lowest per female parasitism $(10.76 \pm 0.89)$ was recorded on $B$ cucurbitae $(P<0.05)$. Percent parasitism also showed the same trend. Adult emergence percentage of $D$. giffardii did not differ significantly among all the three Bactrocera spp. However, the highest $(94.17 \pm 2.67 \%)$ was recorded on pupae of $B$. zonata followed by $91.20 \pm$ $3.23 \%$ on pupae of $B$. dorsalis $(P>0.05)$.

Sex ratio of the emerged parasitoids (Figure 1) revealed that maximum percent females $(61.64 \pm 2.67)$ were recorded from pupae of B. cucurbitae which were statistically at par with percent females emerged from pupae of 
B. zonata $(59.27 \pm 3.17)$. Whereas significantly the lowest female percentage was recorded from pupae of $B$. dorsalis $(52.47 \pm 2.58)(P<0.05)$.

Per female parasitism by $D$. longicaudata was significantly the highest (Table 2) on larvae of $B$. zonata $(26.40 \pm 1.79)$ followed by parasitism on the larvae of $B$. dorsalis and B. cucurbitae $(22.16 \pm 1.07 \& 20.52 \pm 0.81$, respectively) $(\mathrm{P}<0.05)$. It is important to note that parasitism rate of $D$. longicaudata on $B$. dorsalis and $B$. cucurbitae were found insignificantly different. The same sequence was also true for percent parasitism. Likewise, maximum adult emergence percentage was recorded on B. zonata $(93.41$ \pm 2.54 ) followed by B. dorsalis (92.04 \pm 1.59). The lowest adult emergence percentage $(91.26 \pm 2.35)$ was recorded on $B$. cucurbitae. However, the same was found non-significantly different among all the treatments $(P>0.05)$.

Sex ratio of the emerged parasitoids revealed that the percent females of $D$. longicaudata from all the three species of Bactrocera did not differ significantly (Figure 2). However highest percentage of females $(57.75 \pm 3.6)$ was recorded on $B$. cucurbitae followed by $B$. dorsalis (555.18 \pm 4.13$)$.
Parasitism rate (per female) of $A$. daci was significantly the highest on larvae of $B$. zonata $(24.88 \pm 2.01)$ followed by parasitism of $21.72 \pm 1.12$ and $21.56 \pm 1.23$ on larvae of B. dorsalis and B. cucurbitae, respectively ( $\mathrm{P}$ $<0.05)$. Parasitism rate of $A$. daci for the latter two species of Bactrocera was found statistically insignificant. Percent adult emergence of $A$. daci also did not differ significantly among all the treatments, however, the highest $(93.84 \pm 3.14)$ was recorded on B. zonata and the lowest (91.59 \pm 3.23 ) on B. cucurbitae (Table 3).

Sex ratio of $A$. daci showed that percent females from the emerged parasitoids were the highest $(54.2 \pm 3.44)$ on $B$. dorsalis followed by $B$. zonata $(53.73 \pm 4.16)$. Lowest female percentage $(52.64 \pm 3.56)$ was recorded on B. cucurbitae. However, sex ratio in term of percent females did not show significant differences (Figure 3).

Relative collective parasitism per female by all the three fruit fly parasitoids revealed that highest parasitism rate $(23.7 \pm 2.26)$ was exhibited by $D$. longicaudata followed by $A$. daci $(22.72 \pm 2.14)$. Significantly the lowest parasitism rate was showed by $D$ giffardii $(14.43 \pm 1.89)$ (Figure 4).

Table 1. Parasitism potential of $D$. giffardii on pupae of three Bactrocera species

\begin{tabular}{|c|c|c|c|}
\hline Treatment & Parasitism/female & \% Parasitism & \% Emergence \\
\hline B. zonata & $16.72 \pm 1.67 \mathrm{a}$ & $8.36 \pm 1.12 \mathrm{a}$ & $94.17 \pm 2.67 \mathrm{a}$ \\
\hline B. dorsalis & $15.04 \pm 0.87 \mathrm{a}$ & $7.90 \pm 1.05 \mathrm{a}$ & $91.20 \pm 3.23 \mathrm{a}$ \\
\hline B. cucurbitae & $10.76 \pm 0.89 \mathrm{~b}$ & $5.38 \pm 0.84 \mathrm{~b}$ & $88.32 \pm 4.12 \mathrm{a}$ \\
\hline F-ratio & 13.95 & 16.23 & 0.96 \\
\hline P value & 0.001 & 0.001 & 0.410 \\
\hline
\end{tabular}

Means followed by different letters within a column show significant differences $(P<0.05)$ 


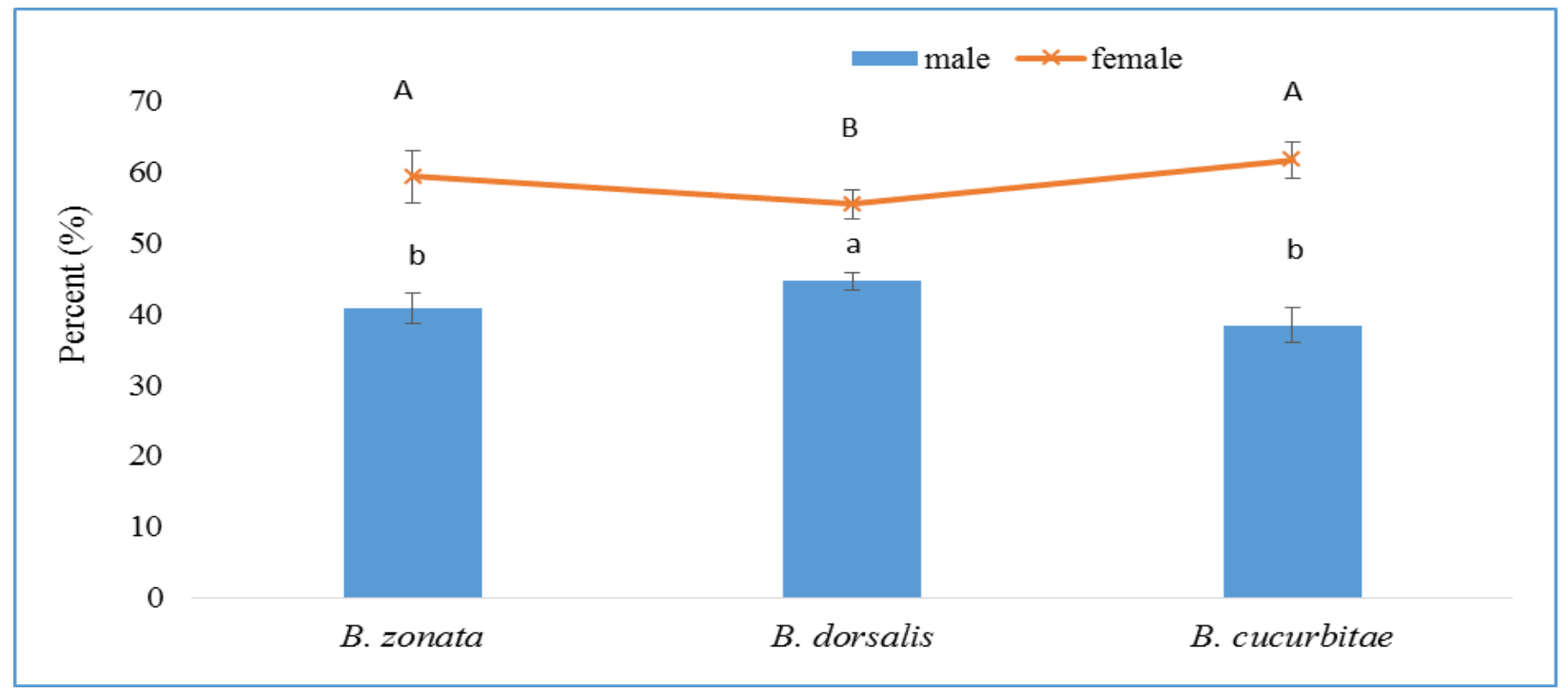

Figure 1. Sex ratio (percent males \& females) of $D$. giffardii on pupae of different Bactrocera spp. (capital and small letters show comparison among female and male parasitoids, respectively)

Table 2. Parasitism potential of $\boldsymbol{D}$. longicaudata on larvae of three Bactrocera species

\begin{tabular}{|c|c|c|c|}
\hline Treatment & Parasitism/female & \% Parasitism & \% Emergence \\
\hline B. zonata & $26.40 \pm 1.79 \mathrm{a}$ & $13.70 \pm 1.23 \mathrm{a}$ & $93.41 \pm 2.54 \mathrm{a}$ \\
\hline B. dorsalis & $22.16 \pm 1.07 \mathrm{~b}$ & $11.08 \pm 0.88 \mathrm{~b}$ & $92.04 \pm 1.59 \mathrm{a}$ \\
\hline B. cucurbitae & $20.52 \pm 0.81 \mathrm{~b}$ & $10.26 \pm 1.04 \mathrm{~b}$ & $91.26 \pm 2.35 \mathrm{a}$ \\
\hline F-ratio & 15.59 & 12.43 & 0.47 \\
\hline P value & 0.0001 & 0.001 & 0.63 \\
\hline
\end{tabular}

Means followed by different letters within a column show significant differences $(P<0.05)$

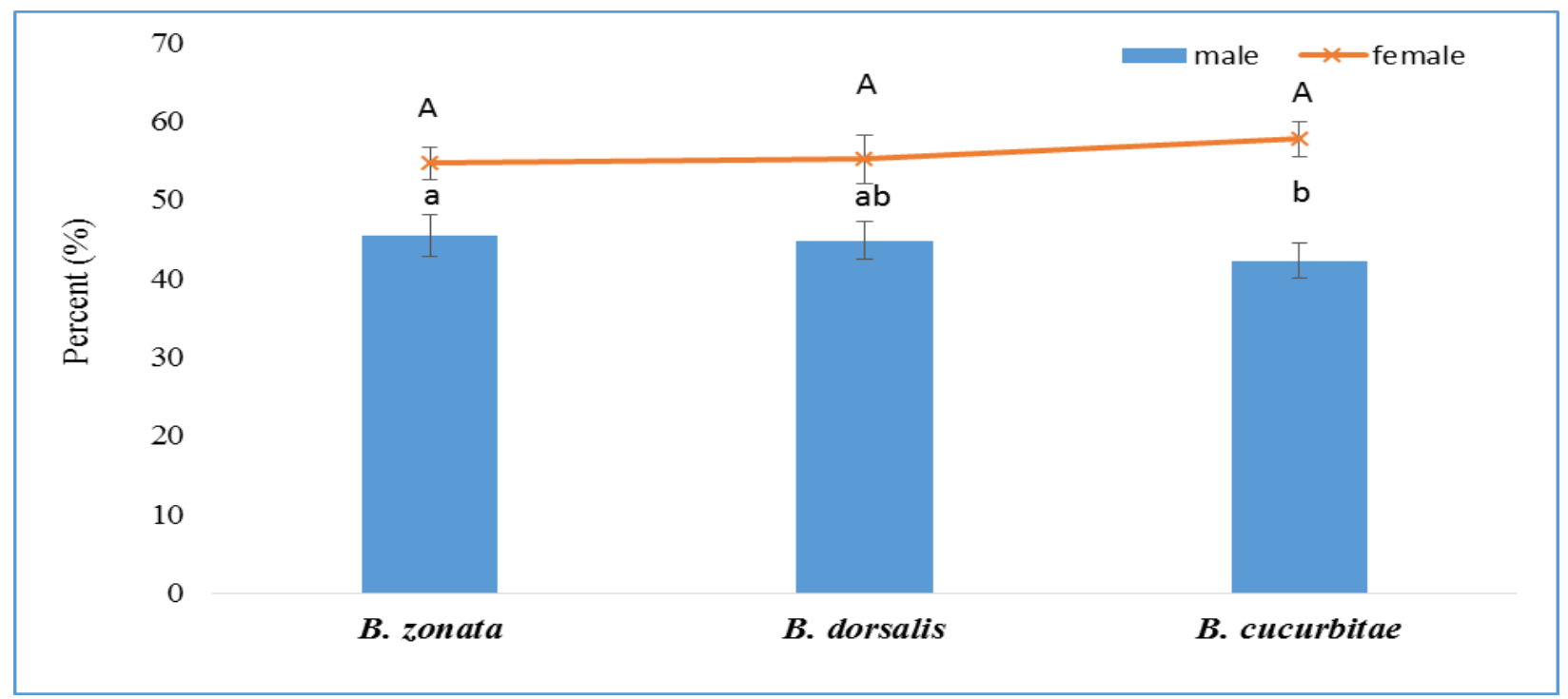

Figure 2. Sex ratio (percent males \& females) of $D$. longicaudata on larvae of different Bactrocera spp. (capital and small letters each show comparison among female and male parasitoids, respectively) 
Table 3. Parasitism potential of A. daci on larvae of three Bactrocera species

\begin{tabular}{|c|c|c|c|}
\hline Treatment & Parasitism/female & \% Parasitism & \% Emergence \\
\hline B. zonata & $24.88 \pm 2.01 \mathrm{a}$ & $12.44 \pm 1.67 \mathrm{a}$ & $93.84 \pm 3.14 \mathrm{a}$ \\
\hline B. dorsalis & $21.72 \pm 1.12 \mathrm{~b}$ & $10.86 \pm 1.03 \mathrm{~b}$ & $92.47 \pm 2.65 \mathrm{a}$ \\
\hline B. cucurbitae & $21.56 \pm 1.23 \mathrm{~b}$ & $10.78 \pm 1.11 \mathrm{~b}$ & $91.59 \pm 3.23 \mathrm{a}$ \\
\hline F-ratio & 13.17 & 11.64 & 0.41 \\
\hline P value & 0.001 & 0.001 & 0.68 \\
\hline
\end{tabular}

Means followed by different letters in each column show significant differences $(P<0.05)$

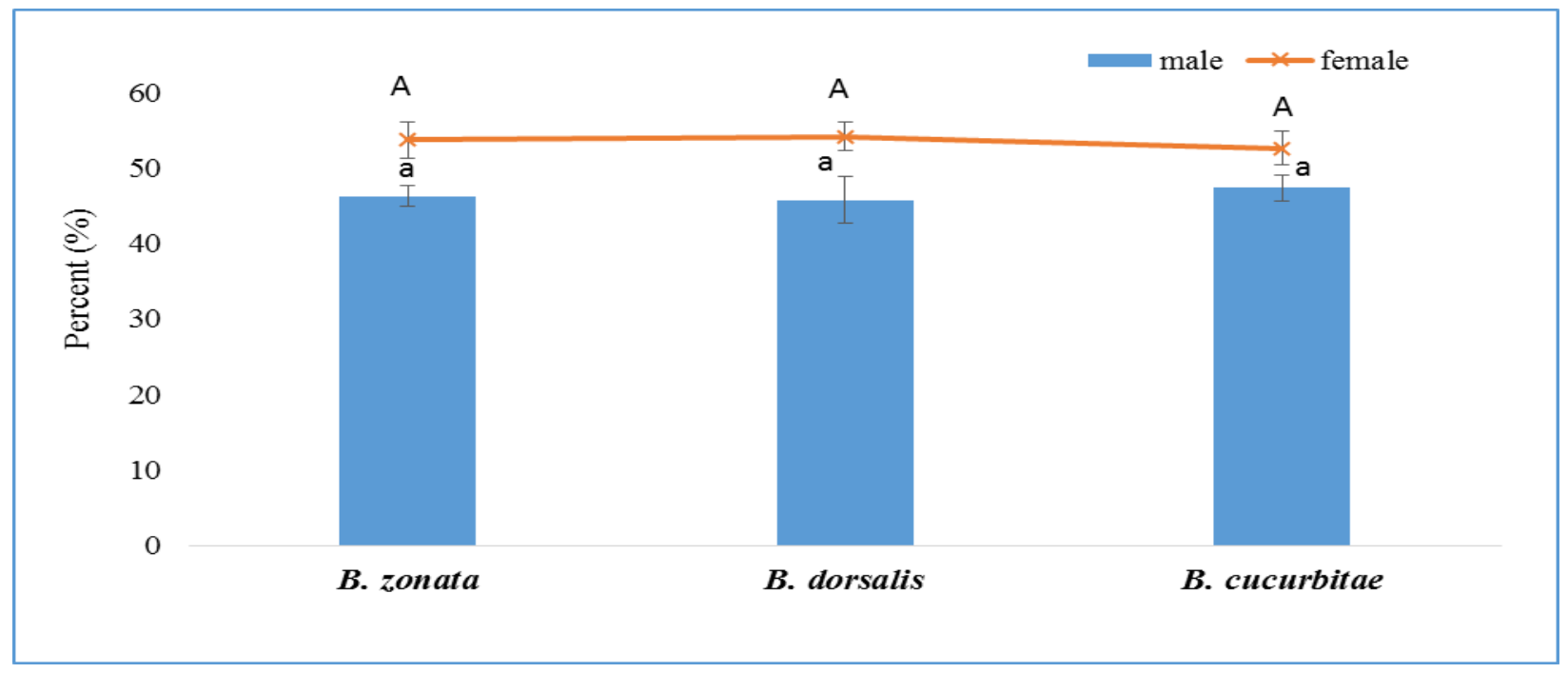

Figure 3. Sex ratio (percent males \& females) of $A$. daci on larvae of different Bactrocera spp. (capital and small letters each show comparison among female and male parasitoids, respectively)

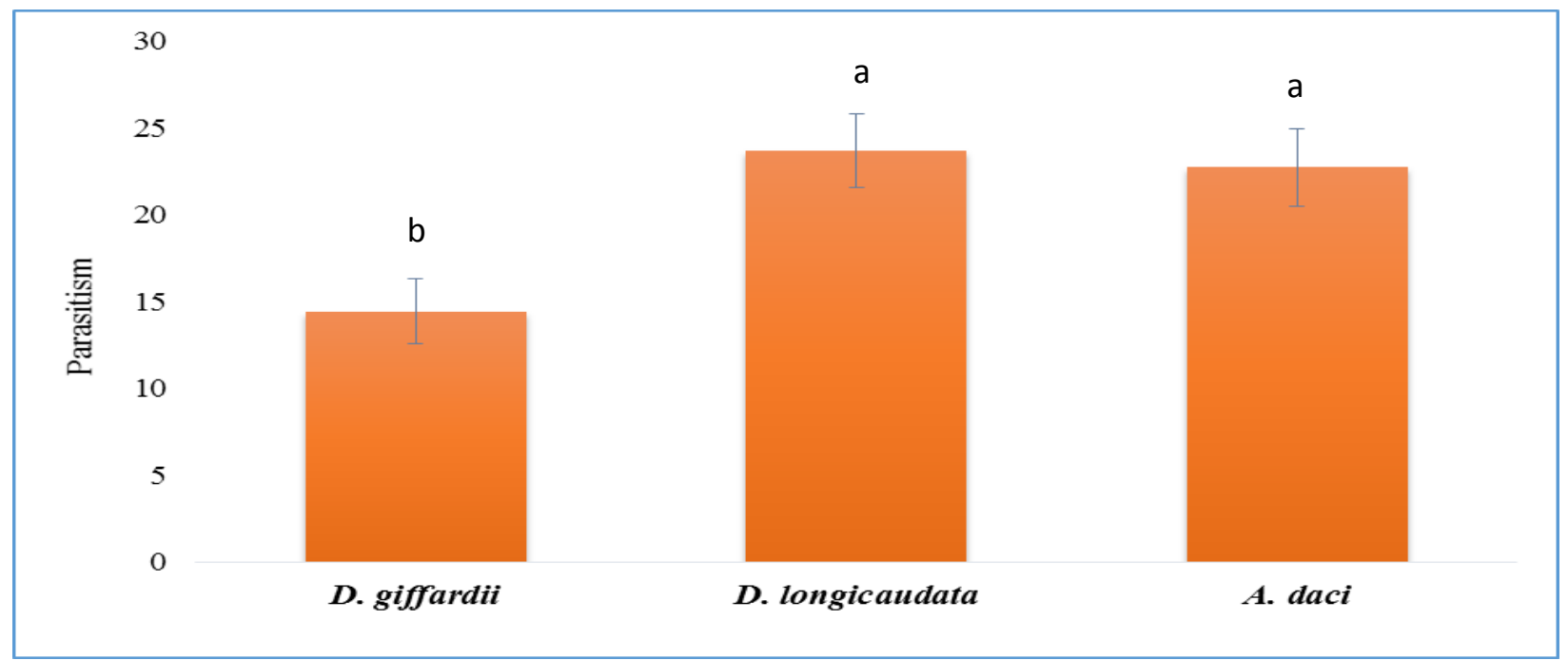

Figure 4. Relative collective per female parasitism rate of $D$. giffardii, $D$. longicaudata and $A$. daci towards different fruit fly species 


\section{Discussion}

Results of the present studies manifested that the pupal parasitoid, D. giffardii exhibited higher rate of parasitism on pupae of $B$. zonata and $B$. dorsalis, which are almost of identical size, compared to B. cucurbitae. Pupae of the latter is bigger compared to other two fruit fly species. This higher parasitism rate of $D$. giffardii, irrespective of the size, could be attributed to nutritional fitness of the host for the parasitoid [24-26] due to which a particular host receive high degree of parasitism. While locating host for oviposition, most of the parasitoids usually determine the quality of the host in term of nutrition [27, 28] which affect their preferences and hence parasitism potential. It is also worth mentioning that different host pupae have different cues perceived by the parasitoids which in turn may affect parasitism rate of a particular parasitoid [26]. However, contrary to our findings, many earlier workers reported higher parasitism rate on bigger size host while referring to positive correlation of host size with parasitism rate [29-31].

Larval-pupal parasitoids, D. longicaudata and $A$. daci showed significantly higher parasitism on $B$. zonata compared to $B$. dorsalis and $B$. cucurbitae. Whereas parasitism rate on larvae of $B$. dorsalis and cucurbitae did not differ significantly. Apart from factors discussed above for $D$. giffardii, higher parasitism potential of $A$. daci for $B$. zonata could also be attributed to innate preference of the parasitoid for this particular fruit fly species. Difference in larval cues for attraction of parasitoid may also be one of the reasons that led to higher parasitism on $B$. zonata compared to other two species. These chemical cues emanated from host larvae play important role in the process of host acceptance [32]. Contrary to this, [33] reported parasitism of $D$. longicaudata at similar rates on larvae of $C$. capitata and $A$. fraterculus in no choice test. It is also worth mentioning that the time spent by a particular parasitoid for oviposition may be different for different host species which may affect the rate of parasitism. The sex ratio of the emerged parasitoids (D. giffardii, $D$. longicaudata and $A$. daci) from all the fruit fly species was slightly skewed in favour of females. Statistical comparison of female parasitoids of $D$. longicaudata and $D$. giffardii emerged from all three species of fruit flies showed non-significant differences. The reason for higher female percentage could be the higher sensitivity of males than females as some males might have died in the embryonic stage. [17] Reported that the biased sex ratio towards females of D. longicaudata may be linked to good quality and suitable age of the host that encourage parasitoids for female eggs oviposition. Conversely, females with poor food quality usually produce more male offspring.

In conclusion of the present studies, B. zonata appeared to be the most favorable host for laboratory rearing and multiplication of all the three parasitoids, D. giffardii, $D$. longicaudata and A. daci on account of higher parasitism rate and adult emergence percentage. On the other hand, B. cucurbitae could be considered as least favorable host compared to $B$. dorsalis where lowest parasitism rate was recorded. However, further studies are also needed to provide a better understanding about the parasitism behavior of these parasitoids.

\section{Authors' contributions}

Conceived and designed the experiments: MH Khan \& NH Khuhro, Performed the experiments: $\mathrm{MH}$ Khan, M Awais \& MU Asif, Analyzed the data: MH Khan \& RM Memon, Contributed reagents/ materials/ analysis tools: $\mathrm{MH}$ Khan, $\mathrm{M}$ Awais, RM Memon \& MU Asif, Wrote the paper: MH Khan \& NH Khuhro. 


\section{Acknowledgements}

The authors are highly thankful to Muhammad Yousuf Memon, Director Nuclear Institute of Agriculture, Tandojam for his help in the provision of resources used in this work.

\section{References}

1. Stephens AEA, Kriticos DJ \& Leriche A (2007). The current and future potential geographical distribution of the oriental fruit fly, Bactrocera dorsalis (Diptera: Tephritidae). Bull Entomol Res 97: 369-378.

2. Permalloo S, Seewooruthun SI, Joomaye A, Soonnoo AR, Gungah B, Unmole L, Boodram R (1998). Repot on "area wide control of fruit flies in Mauritius", pp 203210.

3. Peck SL \& McQuate GT (2004). Ecological Aspects of Bactrocera latifrons (Diptera: Tephritidae) on Maui, Hawaii: Movement and Host Preference. Environ Entomol 33.

4. Anonymous (2009). Agricultural Statistics of Pakistan, 2008-2009. Govt. of Pak. Mini. Food, Agric. Livestock (Economic Wing), Islamabad.

5. Mahmood K \& Mishkatullah (2007). Population Dynamics of Three Species of Genus Bactrocera (Diptera: Tephritidae: Dacinae) in BARI, Chakwal (Punjab) Pak J Zool 39(2): 123-126.

6. Ali I, Farmanullah \& Khan SA (1999). Efficacy of various insecticides and trap heights in methyl eugenol baited traps against fruit flies (Bactrocera spp.). Sarhad J Agric 15(6): 589-594.

7. Ahmad B, Anjum R, Ahmad A, Yousaf MM, Hussain M, \& Muhammad W (2005). Comparison of different methods to control fruit fly (Carpomyia vesuviana) on ber (Zizyphus mauritiana). Pak Entomol 27: 12.

8. Vargas G, Gómez LA \& Michaud JP (2015). Sugarcane stem borers of the Colombian Cauca River Valley: pest status, biology and control. Fla Entomol 98: 728-735.

9. Dinham B (1993). The Pesticides Hazard: A Global Health and Environmental Audit, Zed Books, London (UK), pp 228.

10. Van Lenteren JC (2012). The state of commercial augmentative biological control: plenty of natural enemies, but a frustrating lack of uptake. Bio Control 57(1): $1-20$.

11. Ashraf M, Fatima B, Hussain T, Ahmad N, Hong LW \& Sastroutomo SS (1999). Biological control: an essential component of IPM programme for sugarcane borers. Proc Symp Biol Control Tropics 38-42.

12. Clausen CP, Clancy PW \& Chock QC (1965). Biological control of the oriental fruit fly (Dacus dorsalis Hendel) and other tropical fruit flies in Hawaii. United States Department of Agriculture (USDA) Technical Bulletin 1322, pp. 102.

13. Papadopoulos NT \& Katsoyannos BI (2003). Field parasitism of Ceratitis capitata larvae by Aganaspis daci in Chios, Greece. Bio Control 48: 191-195.

14. El-Heneidy A (2017). Adaptation and first field release of Aganaspis daci (Weld), a larval parasitoid of the peach fruit fly, Bactrocera zonata (Saund.), in Egypt. Proc. 9th ISFFEI - ISBN: 978-616-358-207-2 (2016) 395-400.

15. Noyes JS (2001). Interactive catalogue of world Chalcidoidea. Electronic compact disc by Taxapad, Vancouver Canada and the Natural History Museum, London 2002.

16. Rousse P, Gourdon F \& Quilici S (2006). Host specificity of the egg pupal parasitoid Fopius arisanus (Hymenoptera: Braconidae) in La Reunion. Biol Control 2006: 37(3): 284-290.

17. Wharton RA (1989). Classical biological control of fruit Tephritidae: in Robinson A, Harper G, Eds. World crop pests, fruit flies: their biology, natural enemies, and control. vol. 3b. Elsevier, Amsterdam, pp 303-313.

18. Guido A, Nieuwenhove V \& Ovruski SM (2011). Influence of Anastrepha fraterculus (Diptera: Tephritidae) larval instars on the production of Diachasmimorpha longicaudata (Hymneoptera: Braconidae) progeny and their sex ratio. Fla Entomol 94(4): 863-868.

19. Purcell MF (1998). Contribution of biological control to integrated pest management of tephritid fruit flies in the tropics and subtropics. Inter Pest Manag Rev 3: 63-83. 
20. Andleeb S, Shahid MS \& Mehmood R (2010). Biology of Parasitoid Aganaspis daci (Weld) (Hymenoptera: Eucoilidae). Pak J Sci Ind Res 53(4): 201-204.

21. Hendrichs J, Kenneth B, Gernot H, James EC, Patrick G \& Alan SR (2009). Improving the cost-effectiveness, trade and safety of biological control for agricultural insect pests using nuclear techniques. Biocontrol Sci Technol 19: 3-22.

22. Klungness LM, Jang EB, Ronald FL, Vargas RI, Sugano JS \& Fujitani E (2005). New sanitation techniques for controlling tephritid fruit flies (Diptera: Tephritidae) in Hawaii. J Appl Sci Environ Manag 9: 5-14.

23. Sørensen G, Jesper, Addison MF \& Terblanche J (2012). Mass-rearing of insects for pest management: Challenges, synergies and advances from evolutionary physiology. Crop Prot 38: 87-94.

24. Harvey JA \& Strand MR (2002). The developmental strategies of endoparasitoid wasps vary with host feeding ecology. Ecology 83: 2439-2451.

25. Roriz V, Oliveira L \& Garcia P (2006). Host suit- ability and preference studies of Trichogramma cordubensis (Hymenoptera: Trichogrammatidae). Biol Control 36: 331336.

26. Zhao HY, Zeng L, Xu YJ, Lu YY \& Liang GW (2013). Effects of host age on the parasitism of Pachycrepoideus vindemmiae (Hymenoptera: Pteromalidae), an ectoparasitic pupal parasitoid of Bactrocera cucurbitae (Diptera: Tephritidae). Fla Entomol 96(2): 451-457.

27. Chinwada P, Overholt WA, Omwega CO \& Muek JM (2003). Geographic differences in host acceptance and suitability of two Cotesia sesamiae populations in Zimbabwe. Biol Control 28: 354-359.
28. Li JC, Thomas A, Coudron PWL, Liu XX, Lu ZY \& Zhang QW (2006). Host age preference of Microplitis mediator (Hymenoptera: Braconidae), an endoparasitoid of Mythimna separate (Lepidoptera: Noctuidae). Biol Control 39: 257-261.

29. Wang XG \& Messing RH (2004). Potential interactions between pupal and egg or larvalpupal parasitoids of tephrritid fruit flies. Environ Entomol 33(5): 1313-1320.

30. Cancino J, Villalobos $\mathrm{P} \&$ De La Torre $\mathrm{S}$ 2002. Changes in the rearing process to improve the quality of mass production of the fruit fly parasitoid Diachasmimorpha longicaudata (Ashmead) (Hymenoptera: Braconidae), pp 74-82. In NC Leppla, KA Bloem, and RF Luck [eds.], Quality Control for Mass-reared Arthropods. Proc 8th and 9th work- shop of the IOBC, Florida, USA.

31. López OP, Hénaut Y, Cancino J, Lambin M, Cruz-López L \& Rojas JC (2009). Is host size an indicator of quality in the massreared parasitoid Diachasmimorpha longicaudata (Hymenoptera: Braconidae). Florida Entomol 92(3): 441-449.

32. Wong TTY \& Ramadan MM (1992). Mass rearing biology of larval parasitoids (Hymenoptera: Braconidae: Opiinae) of tephritid flies (Diptera: Tephritidae) in Hawaii, pp 405-426 In T. E. Anderson and N. C. Leppla [eds.], Advances in Insect Rearing for Research and Pest Management. Westview Press, San Francisco, USA.

33. Ovruski SM, Bezdjian LP, Van Nieuwenhove GA, Albornoz-Medina P. \& Schliserman P (2011). Host preference by Diachasmimorpha longicaudata (Hymneoptera: Braconidae) reared on larvae of Anastrepha fraterculus and Ceratitis capitata (Diptera: Tephritidae). Fla Entomol 94(2): 195-200. 